\title{
Effects of endurance exercise and estrogen supplementation on the proliferation of satellite cells
}

\author{
Nader Tanideh • Homa Shahin Sheikhani • Mohsen Salesi • \\ Amin Tamadon • Katiyoon Rostamzad • Ahsan Kardeh
}

Received: 20 August 2013 / Accepted: 30 October 2013 /Published online: 15 November 2013

(C) Springer-Verlag London 2013

\begin{abstract}
Animal and human studies indicated that overtension and stress release inflammatory substances and growth factors that are produced following exercise, which leads to satellite cell activation and proliferation. The aim of the present study was to investigate the effect of an 8-week endurance exercise and estrogen supplementation on the proliferation of satellite cells in rats. Seventy-six rats were selected and randomly divided into two equal groups, ovariectomized and intact groups. Both groups were randomly divided into four subgroups as follows: endurance exercise, estrogen supplementation, estrogen supplementation with endurance exercise, and control. Then, the endurance exercise group and estrogen supplementation with endurance exercise group performed endurance exercise for 8 weeks, three sessions per week. In each week, the estrogen supplementation group and estrogen supplementation with endurance exercise group were injected subcutaneously with $3 \mathrm{mg} / \mathrm{kg}$ of estradiol benzoate.
\end{abstract}

N. Tanideh $\cdot$ A. Tamadon

Stem Cell and Transgenic Technology Research Center, Shiraz

University of Medical Sciences, Shiraz, Iran

N. Tanideh $(\bowtie)$

Pharmacology Department, Shiraz University of Medical Sciences,

Shiraz, Iran

e-mail: nadertanideh@yahoo.com

H. Shahin Sheikhani

Department of Physical Education and Sport Sciences, Kharazmi

University, Tehran, Iran

M. Salesi

Department of Physical Education, College of Education and

Psychology, Shiraz University, Shiraz, Iran

K. Rostamzad

Farhangian University, Shiraz, Iran

A. Kardeh

Bushehr University of Medical Sciences, Bushehr, Iran
The soleus muscle was retracted and placed into $10 \%$ buffered formalin solution. In a pathological lab, the number of satellite cells was counted and recorded using a light microscope through hematoxylin and eosin staining and immunohistochemistry for CD56. Increase in satellite cell number was significant in the two groups of intact rats treated with estrogen supplementation and the ovariectomized rats which performed endurance exercise. The comparison of these groups' means demonstrated that the satellite cell number increased more in the ovariectomized rats. Endurance exercise and estrogen supplementation can increase the proliferation of satellite cells in the rat's soleus muscle.

Keywords Endurance exercise $\cdot$ Estrogen $\cdot$ Satellite cell $\cdot$ Rat

\section{Introduction}

Eccentric and unaccustomed exercise or exercises involving contractions lead to myofibril injury (Friden and Lieber 1992) which can regenerate after pathological injuries in the muscle. A sequence of events induces muscle regeneration and briefly included infiltration of inflammatory cells (e.g., neutrophil and macrophage) into the damaged area following the activation of satellite cells to regenerate the damaged tissue (Armstrong et al. 1991). Satellite cells are myogenic precursor, quiescent, located between the basal membrane and plasma membrane in adult muscles, and responsible for muscle regeneration.

Most of the studies investigating the effects of exercise on satellite cells have reported a significant increase in the number of satellite cells following resistance exercise resulting in muscle hypertrophy (Mackey et al. 2007). Thus, this increase in cell number is associated with supra structural damages and release of growth factors (Kadi et al. 2005). Besides, researchers have stated that different types of long-term exercise 
cause the satellite cells in human body muscles to activate and proliferate (Charifi et al. 2003).

Estrogen supplementation can affect satellite cell activation and proliferation following muscle injury after lengthening contractions and can attenuate post-damaged neutrophil infiltration in skeletal muscles (Tiidus et al. 2001). Hence, it can be stated that estrogen has a significant role as a stimulator in the repair of muscle and activation and proliferation of satellite cells following injury (Enns and Tiidus 2010). Kurosaka et al. (2009) suggested that distance training increases satellite cell proliferation and can be used as preconditioning to increase muscle volume and to improve muscle function.

Research on animals have specified that there are differences in distance training protocol responses, and these changes are effects of the estrogen influence on skeletal muscles since the differences were observed in hormonal dysfunction in animals (Tiidus 2003). Moran et al. (2006) proved that ovariectomy decreases the contractile capacity of skeletal muscles in mature female rats and related damages with lack of myosin availability to strong conjunction during contraction. It is possible that estrogen has a protective effect on muscle damage by a direct effect on contraction function. Brown et al. (2012) investigated the ovariectomy effects and estrogen replacement in muscle mass recovery after reloading and weightlessness in older rats. They found out that the recovery of the muscles of the ovariectomized rats was poor, while that of the estrogen-supplemented rats was quick. They suggested that estrogen supplementation plays the main role in increasing post-exercise muscle satellite cell proliferation (Brown et al. 2012). Enns and Tiidus (2008) examined the effect of estrogen on satellite cell activation and proliferation following downhill running in ovariectomized rats, and the study results demonstrated that estrogen supplementation affects satellite cell activation and proliferation following muscle injury after lengthening contractions.

Although estrogen supplementation leads to increase in the number of satellite cells following muscle damage, proliferation of such cells to regenerate and repair the muscle is vital (Tiidus et al. 2005), and once women reach menopause, estrogen concentration and other female hormones decrease and result in many side effects including increase in potential damage and delay in recovery following damage (Enns and Tiidus 2010).

Since the skeletal muscles cannot regenerate the damage without the presence of satellite cells, the comparison of the two conditions seem warranted because the understanding of regeneration mechanisms in post-sport injuries can shed light on those practical strategies which enhance the regeneration process. The aim of the present study was to investigate whether or not endurance exercise can increase the satellite cell numbers in female rats, the same as estrogen supplementation. Therefore, the effects of 8 weeks of endurance exercise and estrogen supplementation on the satellite cells in rats were compared.

\section{Materials and methods}

Ethics approval for this project was obtained from Shiraz University of Medical Sciences Ethics Committee and done according to the recommendations of the Animal Care Committee of the Shiraz University of Medical Sciences with the code number of 90-01-67-4128. Seventy-six female SpragueDawley rats (Rattus norvegicus) weighing $200 \pm 20 \mathrm{~g}$ were randomly selected and housed in the Laboratory Animal Center of Shiraz University of Medical Sciences, Shiraz, Iran under controlled temperature $\left(22^{\circ} \mathrm{C}\right)$ and lighting $(12: 12$ light-to-dark ratio; light on at 7:30A.M.) conditions in transparent polycarbonate cages with $(54 \times 18 \times 18 \mathrm{~cm})$ dimensions for 3 months. The rats were randomly divided into equal ovariectomized and intact groups $(n=38)$. After 1-month full recovery of ovariectomized rats, both groups were randomly subdivided into four subgroups as follows: endurance exercise $(n=11)$, estrogen supplementation $(n=11)$, estrogen supplementation with endurance exercise $(n=11)$, and control $(n=5)$.

Estrogen supplement $(3 \mathrm{mg} / \mathrm{kg}$ estradiol benzoate, Vetastrol $^{\circledR}$, Aburaihan Co., Iran) was injected subcutaneously weekly for 8 weeks. Endurance exercise was performed for 8 weeks and three sessions in each week. Training program consisted of two stages: (1) adaptation stage. In this stage, the rats ran on a treadmill (Turbo fitness 200, Taiwan) at the speed of $12 \mathrm{~m} / \mathrm{min}, 15$ to $20 \mathrm{~min}$ daily for 5 days. (2) Overloading stage was performed according to an incremental program (Table 1). In the last week of overloading stage, the rats ran for $50 \mathrm{~min}$ with $30-\mathrm{m} / \mathrm{min}$ intensity, and the intensity was estimated at about 70 to $80 \% \mathrm{VO}_{2} \max$ (Chung et al. 2006).

At the end of the eighth week, the rats were sacrificed, and their soleus muscles were harvested, embedded in $10 \%$ buffered formalin solution, cut into serial transverse sections of $5-\mu \mathrm{m}$ thickness, stained with hematoxylin-eosin, and subjected to immunohistochemistry for CD56. For antigen retrieval, TE buffer at $\mathrm{pH} 9$ was used for 20 min. Primary antibody CD56 (clone 123c3) with dilution of $1 / 200$ was incubated with the tissue of muscle overnight. The tissues were stained with DAB and visualized, and counterstaining was performed using hematoxylin-eosin (Fig. 1). Positive CD56 satellite cells in rats' muscle were counted using a light microscope, and an average of 50 fields was recorded by an expert pathologist who was blinded to the study groups. The number of positive CD56

Table 1 Duration and intensity of 8-week incremental training program of race rats on treadmill

\begin{tabular}{lllllllll}
\hline & \multicolumn{1}{l}{ Week } & & & & & & \\
\cline { 2 - 8 } & 1 & 2 & 3 & 4 & 5 & 6 & 7 & 8 \\
\hline Intensity (m/min) & 18 & 18 & 24 & 24 & 30 & 30 & 30 & 30 \\
Duration (min) & 25 & 30 & 30 & 35 & 35 & 40 & 45 & 50 \\
\hline
\end{tabular}


Fig. 1 Left, immunohistochemistry for the CD56 shows positive satellite cells (arrow) (×40). Right, hematoxylin-eosin-stained section of one of the muscle biopsies $(\times 100)$

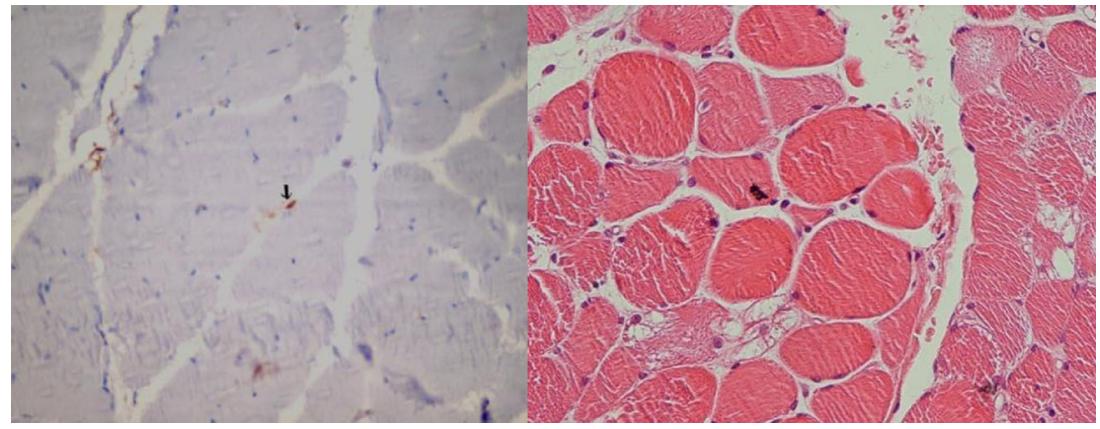

satellite cells in rats' muscle between the different groups was compared by Mann-Whitney $U$ test using statistical package for social sciences (SPSS) version 11.5 (SPSS Inc, Chicago, IL, USA). A $P \leq 0.003$ was considered statistically significant.

\section{Results}

Proliferation of satellite cells in the estrogen supplementation group was significantly higher than that in the control group $(P=0.002)$, while that in the estrogen supplementation with endurance exercise group was less than that in the control group $(P=0.002$; Fig. 2). However, the satellite cells increased in the group receiving estrogen in comparison with those of the endurance exercise group $(P<0.001)$. Moreover, $40 \%$ $(P<0.001)$ and more than $200 \%(P<0.001)$ increases were observed in the satellite cell proliferation in the endurance exercise and estrogen supplementation groups, respectively in comparison with that in the estrogen supplementation with endurance exercise group.

The satellite cells decreased by $26 \%(P=0.003)$ and $32 \%$ $(P=0.002)$ in the estrogen supplementation with endurance exercise and estrogen supplementation groups, respectively, compared to that in the control (Fig. 2). However, there was an $80 \%(P<0.001)$ and $65 \%(P<0.001)$ increase in the proliferation of satellite cells in the estrogen supplementation and estrogen supplementation with endurance exercise groups, respectively.
The satellite cells increased in the ovariectomized rats in the endurance exercise $(P<0.001)$ and estrogen supplementation with endurance exercise $(P=0.002)$ groups, compared with those in the intact rats (Fig. 2). While in the ovariectomized rats receiving estrogen supplementation for long-term, the satellite cells decreased in comparison with those in the intact rats $(P<0.001)$.

\section{Discussion}

Exercise endurance induced the increase of satellite cells in the soleus muscle of ovariectomized rats. This can be attributed to the injury or rupture inside the myofibers. The injuries are not easily observed by a light microscope, but are important in triggering the response of satellite cells (Tiidus 2008). Satellite cells are monocellular myogenic precursor to repair or remove necrosis muscle fiber and can act as a source of extra muscle nuclei during mature muscle hypertrophy. Furthermore, a strenuous or unaccustomed exercise bout can induce injury of tissues and repair of few fibers (Smith et al. 2001), and can increase satellite cell activation and proliferation in mature rats' slow- and fast-twitch muscle fibers (Hawke and Garry 2001). Evidence proves that some exercise activity repetition induces injury response in muscle, and this can increase tissue repair (Wanek and Snow 2000). Exercise training such as running on treadmill can progressively result in increased satellite cell number and myogenic activation related to morphology changes, which are
Fig. 2 The means of satellite cell numbers in the different groups of intact and ovariectomized rats. Lines show significant different at the level of 0.003 between groups

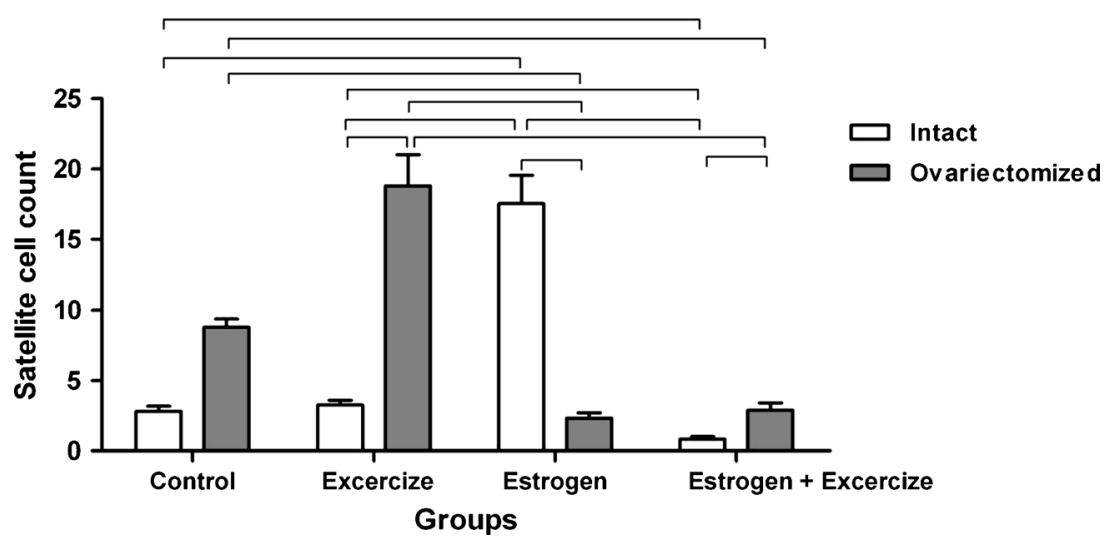


indicators of continuous fiber injury and repair (Umnova and Seene 1991). Consistent with our findings, Charifi et al. (2003) suggested that endurance exercise is considered an appropriate method in improving muscle injuries and muscle performance. Furthermore, Roth et al. (2001) stated that satellite cells make the muscle adapt to the endurance exercise. Therefore, it can be stated that since the produced satellite cells fuse in the exercise fibers, the accumulation or accretion of such newly produced myonuclei would increase available DNA to aid in fiber regeneration, maturation or the potentially adaptive processes. However, the effects of functional loading increase beyond the normal activity levels; satellite cell proliferation and muscular cell accumulation produced during adult muscle regeneration following exercise induced by injury has not been clearly determined.

Estrogen supplementation induced the increase of satellite cells in soleus muscle of intact rats. Previous studies showed that estrogen can augment satellite cell activation (Enns et al. 2008) and limit exercise-induced muscle damage, leukocyte infiltration, and inflammation in animal and human models (Dieli-Conwright et al. 2009a). Both estrogen receptors $\alpha$ and $\beta$ have recently been found in male and female skeletal muscles (Wiik et al. 2009). Estrogen receptor signaling is complex and can involve a number of cascades and second messengers with receptors interacting with each other, acting from both the membrane and cytosolic locations and possibly being activated by factors other than estrogen in various target tissues (Turgeon et al. 2006). There may be other mechanisms by which estrogen can act to positively signal muscle satellite cells (Enns et al. 2008; Thomas et al. 2010). The signaling pathways by which estrogen and estrogen receptor-alpha influence muscle satellite cell function have not yet been elucidated. Numerous possible signaling mechanisms which are influenced by estrogen and estrogen receptors and which also potentially influence muscle satellite cells may be responsible for these effects (Enns and Tiidus 2010). The estrogen receptor co-regulator gene expression is also influenced by estrogen in human muscle cells (Dieli-Conwright et al. 2009b). Estrogen exposure also decreases enzyme efflux in various muscle damage models in rat (Tiidus and Enns 2009).

The results of the present study showed that endurance exercise with estrogen supplementation in ovariectomized rat increased the number of satellite cells in comparison with those in intact rats. Consistent with our findings, the number of fibers containing activated (i.e., MyoD-positive) and proliferating (i.e., BrdU-incorporated) satellite cells induced by exercise was greater in the estrogen-supplemented group compared with that in the sham group (Tiidus et al. 2005). Besides, Brown et al. (2012) examined the effects of ovariectomy and estrogen replacement on muscle mass repair. Ovariectomy affects the number and proliferation of muscle satellite cells after doing exercise (Tiidus 2008) which is consistent with the findings of the present study. Moran et al. (2006) demonstrated that ovariectomy diminished skeletal muscle contractility in adult female rats, and they suggested that the loss was due to a lack of availability of strong-binding myosin during contraction. In a follow-up study by the same laboratory, estrogen replacement restored contractile function and the availability of strong-binding myosin. However, estrogen was not effective in protecting the muscle against eccentric contraction-induced injury (Moran et al. 2007).

Endurance exercise with estrogen supplementation could not increase the satellite cell numbers as compared to estrogen supplementation only. The attenuation of post-exercise muscle inflammatory responses by estrogen, which potentially reduces muscle damage, might also inhibit repair mechanisms since as previously noted, repair muscle mechanisms are signaled in part by inflammatory-related factors. In this regard, it should be noted that despite its attenuating effects on post-exercise inflammatory factors, estrogen will still enhance the factors associated with muscle repair (Enns and Tiidus 2010). St Pierre Schneider et al. (1999) reported that macrophage infiltration was delayed after long contraction. It may be possible that estrogen affects satellite cell activation and muscle regeneration directly through its effects on macrophages (St Pierre Schneider et al. 1999). Different factors such as insulin-like growth factor1 (IGF-1), hepatic growth factor (HGF), interlukin-6, and other factors related to cytokines assist muscles to repair following injury (Mackey et al. 2007). Intervention between those factors and other regulating factors are very helpful in muscle satellite cell activation and muscle repair. However, few studies have demonstrated that estrogen is not effective in concentrating and in increasing the density of these factors, especially IGF-1 and HGF, in skeletal muscles (Enns and Tiidus 2008). Moreover, the effect of estrogen and HGF levels may occur through regulation mechanisms related to incremental synthesis of nitric oxide in the muscle. Therefore, theoretically, estrogen may have a positive effect on the activation of muscle satellite cells (Enns and Tiidus 2010) and consequently on muscle regeneration through increasing satellite cell activator factors like IGF-1 and HGF, and nitric oxide (NO) (Tiidus et al. 2005). Estrogen increases nitric oxide synthesis (NOs) and NO in human and animal models, and can control HGF release following muscle injuries. Furthermore, a NO release and subsequently a NO level decrease lead to reduced activated myoblasts (Anderson 2000). Therefore, estrogen expression can directly increase myoblast activation through stimulation of NO-regulated HGF (Tiidus et al. 2005). This study showed that estrogen supplementation has some effects on satellite cell proliferation in rats, although many different factors play a role in the increase and proliferation of these cells.

\section{Conclusions}

The present study showed that endurance exercise in ovariectomized rats and estrogen in intact rats can increase the 
proliferation of satellite cells in the soleus muscle. But the combination of endurance exercise and estrogen supplementation could not increase the satellite cell numbers, contrary to the individual effects of endurance exercise and estrogen supplementation.

Acknowledgments The authors sincerely thank Vice Chancellor of Research and Technology of Shiraz University of Medical Sciences for the financial support of this project. Special thanks also go to H. Khajehei for his help with language editing.

\section{References}

Anderson JE (2000) A role for nitric oxide in muscle repair: nitric oxidemediated activation of muscle satellite cells. Mol Biol Cell 11:18591874

Armstrong RB, Warren GL, Warren JA (1991) Mechanisms of exerciseinduced muscle fibre injury. Sports Med 12:184-207

Brown M, Ferreira J, Foley A, Hemmann K (2012) A rehabilitation exercise program to remediate skeletal muscle atrophy in an estrogen-deficient organism may be ineffective. Eur J Appl Physiol 112:91-104

Charifi N, Kadi F, Féasson L, Denis C (2003) Effects of endurance training on satellite cell frequency in skeletal muscle of old men. Muscle Nerve 28:87-92

Chung E, Dorton BJ, Diffee GM (2006) Regional myosin heavy chain isoform expression in response to exercise training in old rat myocardium. FASEB J 20:A1447

Dieli-Conwright CM, Spektor TM, Rice JC, Schroeder ET (2009a) Hormone therapy attenuates exercise-induced skeletal muscle damage in postmenopausal women. J Appl Physiol 107:853-858

Dieli-Conwright CM, Spektor TM, Rice JC, Todd Schroeder E (2009b) Oestradiol and SERM treatments influence oestrogen receptor coregulator gene expression in human skeletal muscle cells. Acta Physiol 197:187-196

Enns DL, Iqbal S, Tiidus PM (2008) Oestrogen receptors mediate oestrogen-induced increases in post-exercise rat skeletal muscle satellite cells. Acta Physiol 194:81-93

Enns DL, Tiidus PM (2008) Estrogen influences satellite cell activation and proliferation following downhill running in rats. J Appl Physiol 104:347-353

Enns DL, Tiidus PM (2010) The influence of estrogen on skeletal muscle: sex matters. Sports Med 40:41-58

Friden J, Lieber RL (1992) Structural and mechanical basis of exerciseinduced muscle injury. Med Sci Sports Exerc 24:521-530

Hawke TJ, Garry DJ (2001) Myogenic satellite cells: physiology to molecular biology. J Appl Physiol 91:534-551

Kadi F, Charifi N, Denis C, Lexell J, Andersen JL, Schjerling P, Olsen S, Kjaer M (2005) The behaviour of satellite cells in response to exercise: what have we learned from human studies? Pflügers Archiv Eur J Physiol 451:319-327
Kurosaka M, Naito H, Ogura Y, Kojima A, Goto K, Katamoto S (2009) Effects of voluntary wheel running on satellite cells in the rat plantaris muscle. J Sports Sci Med 8:51-57

Mackey AL, Esmarck B, Kadi F, Koskinen SOA, Kongsgaard M, Sylvestersen A, Hansen JJ, Larsen G, Kjaer M (2007) Enhanced satellite cell proliferation with resistance training in elderly men and women. Scand J Med Sci Sports 17:34-42

Moran AL, Nelson SA, Landisch RM, Warren GL, Lowe DA (2007) Estradiol replacement reverses ovariectomy-induced muscle contractile and myosin dysfunction in mature female mice. J Appl Physiol 102:1387-1393

Moran AL, Warren GL, Lowe DA (2006) Removal of ovarian hormones from mature mice detrimentally affects muscle contractile function and myosin structural distribution. J Appl Physiol 100:548-559

Roth SM, Martel GF, Ivey FM, Lemmer JT, Tracy BL, Metter EJ, Hurley BF, Rogers MA (2001) Skeletal muscle satellite cell characteristics in young and older men and women after heavy resistance strength training. Journals of Gerontology. Series A. Biol Sci Med Sci 56: B240-B247

Smith HK, Maxwell L, Rodgers CD, McKee NH, Plyley MJ (2001) Exercise-enhanced satellite cell proliferation and new myonuclear accretion in rat skeletal muscle. J Appl Physiol 90:1407-1414

St Pierre Schneider B, Correia LA, Cannon JG (1999) Sex differences in leukocyte invasion in injured murine skeletal muscle. Res Nurs Health 22:243-250

Thomas A, Bunyan K, Tiidus PM (2010) Oestrogen receptor-alpha activation augments post-exercise myoblast proliferation. Acta Physiol 198:81-89

Tiidus PM (2003) Influence of estrogen on skeletal muscle damage, inflammation, and repair. Exerc Sport Sci Rev 31:40-44

Tiidus PM (2008) Skeletal muscle damage and repair. Human Kinetics Publishers, IL, USA, p 133

Tiidus PM, Deller M, Liu XL (2005) Oestrogen influence on myogenic satellite cells following downhill running in male rats: a preliminary study. Acta Physiol Scand 184:67-72

Tiidus PM, Enns DL (2009) Comments on point: counterpoint: estrogen and sex do/do not influence post-exercise indexes of muscle damage, inflammation, and repair. J Appl Physiol 106:1010-1012

Tiidus PM, Holden D, Bombardier E, Zajchowski S, Enns D, Belcastro A (2001) Estrogen effect on post-exercise skeletal muscle neutrophil infiltration and calpain activity. Can J Physiol Pharmacol 79:400 406

Turgeon JL, Carr MC, Maki PM, Mendelsohn ME, Wise PM (2006) Complex actions of sex steroids in adipose tissue, the cardiovascular system, and brain: insights from basic science and clinical studies. Endocr Rev 27:575-605

Umnova MM, Seene TP (1991) The effect of increased functional load on the activation of satellite cells in the skeletal muscle of adult rats. Int J Sports Med 12:501-504

Wanek LJ, Snow MH (2000) Activity-induced fiber regeneration in rat soleus muscle. Anat Rec 258:176-185

Wiik A, Ekman M, Johansson O, Jansson E, Esbjörnsson M (2009) Expression of both oestrogen receptor alpha and beta in human skeletal muscle tissue. Histochem Cell Biol 131:181-189 